\title{
ALTERAÇÕES CLIMÁTICAS RESULTANTES DA OCUPAÇÃO AGRÍCOLA NO BRASIL
}

José Roberto Tarifa

\section{INTRODUÇÄO}

O objetivo principal deste artigo é o de avaliar as possíveis mudanças climáticas decorrentes da ocupação agrícola do território brasileiro.

Admite-se que há mudança climática (a nível regional ou de macro-escala) quando se registra variação em um dos atributos principais do clima (temperatura, chuva) em mais de trinta anos consecutivos e denominase oscilação quando a anomalia ocorre em um período menor de tempo.

Uma das maiores dificuldades para este tipo de avaliação é a correta compreensão das variações dos atributos climáticos no tempo e no espaço. As séries de dados meteorológicos de superfície não são suficientemente longas, e apresentam falhas e inconsistências. Por outro lado, nos raros casos com séries de dados longos (100 a 140 anos) de temperatura e chuva (por exemplo, Rio de Janeiro, Campinas e Fortaleza) é muito difícil separar as oscilaçōes climáticas naturais, daquelas decorrentes dos processos antropogênicos. Outra dificuldade considerável é a enorme extensão do território brasileiro (8,5 milhões de $\mathrm{Km} 2$ ), juntamente com a falta de mapas que documentem historicamente as diferentes formas de apropriação agrícola.

Dentro desta perspectiva, o balanço a ser feito será baseado em observaçōes de campo, aliado à análise da estrutura e gênese dos Climas Regionais do Brasil. No caso específico da Amazônia, onde os processos areolares de savanização e desertificação ${ }^{1}$ associados às queimadas e derrubadas da floresta, tem permitido registro de dados (na última década) serão apresentados resultados complementares baseados em análises numéricas e simulaçōes.

As alterações climáticas resultantes das atividades agro-pecuárias e agro-industriais, serão avaliadas em função da magnitude e abrangência dos impactos e modificaçōes no clima. Desta forma, torna-se necessário a caracterização dos controles climáticos de macro escala, bem como suas interaçōes com os ambientes biogeo-físicos.

Assim sendo, a realidade climática deve objetivamente, ser caracterizada por unidades com grandezas escalares diferenciadas, cujas dimensões variam desde o nível zonal até o nível microclimático. Existe, para cada grandeza taxonômica, métodos, técnicas e limites específicos à explicação do fenômeno naquele nível.

No nível zonal, os principais controles climáticos são a latitude, a altitude, a distância dos oceanos e a circulação geral da atmosfera. Os climas zonais podem ser desdobrados em unidades menores (climas regionais) onde outros parâmetros tais como o relevo (forma, orientação e exposição), a freqüência, o regime e a sazonalidade dos sistemas atmosféricos, estruturam unidades climáticas regionais. Os climas regionais, podem ser organizados em unidades menores, dependendo das variações topográficas e do tipo de cobertura do solo. Desta forma, neste nível de tratamento taxonômico do "clima local" passa a ser mais importante a ação modificadora do homem. No entanto, dentre todos os níveis, é o "microclimático" que sofre a maior influência da ação humana, principalmente no que tange às alterações nas propriedades físicas, geométricas e químicas na interface solo-plantas-atmosfera (camada limite planetária).

(*) Laboratório de Climatologia - Departamento de Geografia - USP, Junho de 1992.

(1) Desertificação será entendida como um crescente ressecamento do meio natural em consequência do desequilibrio no balanço hídrico, quando a quantidade de água fornecida pela precipitação torna-se inferior à perdida pela evaporação mais o escoamento. 


\section{AS INTERAÇÕES CLIMA-FLORESTA NA AMAZÓNIA}

A primeira característica fundamental da Amazônia é a sua enorme extensão de terras baixas junto ao Equador, recebendo diariamente uma razoável porcentagem do calor global que chega à Terra. Em segundo, a existência de uma considerável massa oceânica quente justamente na trajetória dos ventos de Nordeste e Leste que sopram o ano todo para dentro da Bacia. E em terceiro, o papel importante desempenhado pela Cordilheira dos Andes, barrando toda circulação zonal (dos. baixos níveis) e afunilando a umidade para o interior, num verdadeiro anfiteatro, sem saída para o vento que sopra do quadrante leste. E por último e não menos importante, a extensa cobertura vegetal associada às diversas fases do ciclo hidrológico. Na realidade, todas essas características se combinam para interagir e modificar a própria circulação atmosférica. Assim a gênese das chuvas na Amazônia dependem fundamentalmente da interação desses fatores.

Resultados obtidos por SALATI, E. (1987) e VILLA NOVA, N. A. \& SALATI, E. (1977) dão conta que aproximadamente $50 \%$ das chuvas amazônicas seriam oriundas da reciclagem do vapor de água. A cobertura vegetal (florestas) tem um papel relevante neste processo através da transpiração, embora a fonte primária de vapor d'água para a Bacia Amazônica seja o Oceano Atlântico. Quando qualquer análise climática se aproxima do solo, estamos na escala microclimática. Dada a importância da cobertura florestal, é portanto dentro dessa perspectiva metodológica que as alterações climáticas decorrentes da sua substituição por pastagens e cultivos devem ser vistos. No caso específico da Amazônia Centro-Ocidental (área continental), o que na realidade ocorre é uma interação entre os níveis micro, local e regional do Clima. Explicando melhor, se você desmata 10 ou $15 \mathrm{Km} 2$ de floresta, você estará alterando apenas o nível microclimático. No entanto, quando essa alteração no ambiente natural é da ordem de milhares de $\mathrm{Km} 2$, e mesmo podendo alcançar num futuro próximo, eventualmente, mais de um milhăo de $\mathrm{Km} 2$, você estará certamente alterando não só o micro, mas o clima local e o próprio nível regional. O que exatamente poderá conduzir a um processo de desertificação e mudança climática. Dados de temperatura do solo em diferentes profundidades medidos pelo INPA (Instituto Nacional de Pesquisas da Amazônia) em am- biente florestado (latossolo) e em área desmatada e cultivada com roçado (areias brancas) nos dão conta se pode alterar o clima local. Observando-se a Figura 1, percebe-se que período seco (julho de 1969) as diferenças são significativas. Em dia de aquecimento máximo (representado pelo dia 25-10-1968) o solo sem mata chega a acusar $8 \mathrm{C}$ a mais que o solo florestado; e mesmo no período da manhã (horário de mínimo aquecimento) a diferença nunca é inferior a $5 \mathrm{C}$. O dia 18-04-1969, tomado como representante de dia tipicamente chuvoso, ainda assim acusa uma temperatura de solo 2 a 3 C inferior àquela ocupada pela mata.

Torna-se importante também salientar que a Floresta equatorial, funciona como um filtro para todos ou quase todos os elementos climáticos. Trabalho de campo realizado em janeiro de 1981 em Carajás (Serra Norte - Amazônia Oriental), demonstran que a precipitação que ocorre fora da mata, continua caindo dentro dela por 2, 3 e até 6 horas após a chuva ter cessado de ocorre. Em virtude deste fato antes mesmo, que o total da chuva precipitada atinja o solo, ele já está evaporando novamente, e começa a aparecer formação de nuvens baixas em cima do topo das árvores. resultados recentes do INPA para a área de Manaus demonstram que esse total pode alcançar $25 \%$ do total precipitado, enquanto a transpiração pelas folhas (de volta à atmosfera) é da ordem aproximada de 50\%, restando, portanto, $25 \%$ para o escoamento global. A dinâmica da água nesse complexo sistema "solo-planta-atmosfera" com uma constante elevada taxa de água em movimento quer do interior para o exterior (e vice-versa) da comunidade vegetal, nos explica porque o interior da mata se mantém constantemente úmido incluindo o solo.

A retirada da cobertura vegetal implica necessariamente numa mudança radical no processo de recepção e velocidade do fluxo de água das chuvas junto ao solo, podendo erodir rapidamente a camada que retém a maior parte dos nutrientes do solo.

O mais importante impacto climático hoje existente e praticado em larga escala na regiāo amazônica é o fogo. excluindo-se consideraçōes à nível zonal e regional sobre a influência das liberações de $\mathrm{CO} 2$ na circulação geral da atmosfera, já são evidentes os seguintes efeitos: 
- destruição de extensas áreas de florestas, princi- rios (principalmente nos estados do Pará, Rondonia e palmente ao longo das rodovias (Transamazônica, BR Acre conforme pode ser observado no Quadro 1).

364, PA 70) para a implatação de projetos agro-pecuá-

FIGURA 1

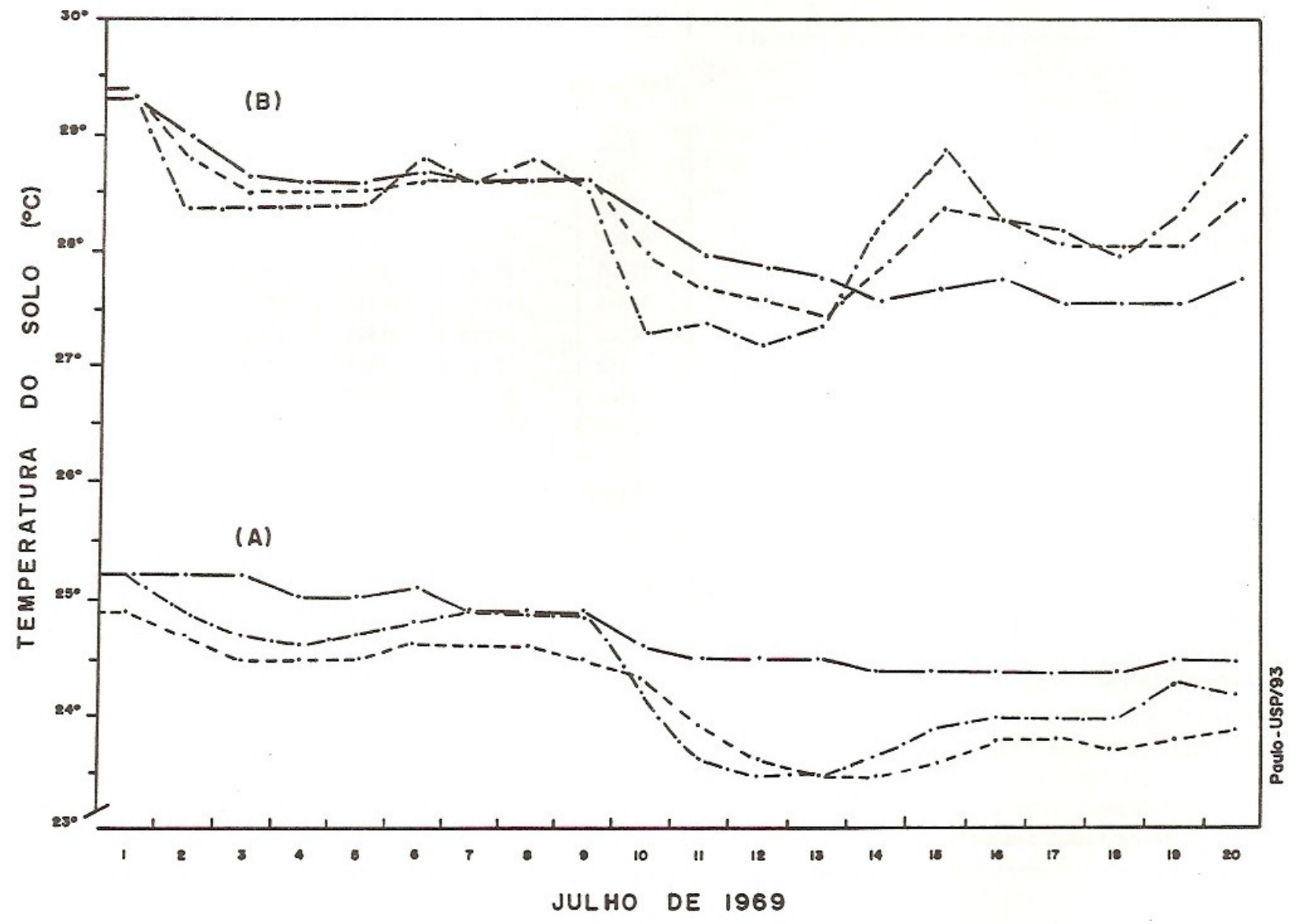

FIGURA 1

VARIACÃO DIÁRIA DA TEMPERATURA DO

SOLO EM SOLOS FLORESTADOS (A) E

SOLOS DE CAPOEIRA (B) NO KM 26

(MANAUS)

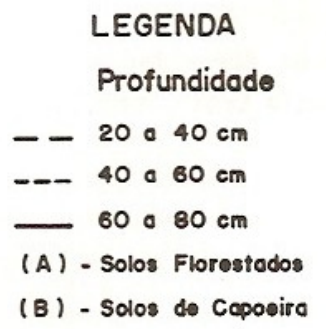


Quadro 1

EXTENSÃO DO DESFLORESTAMENTO

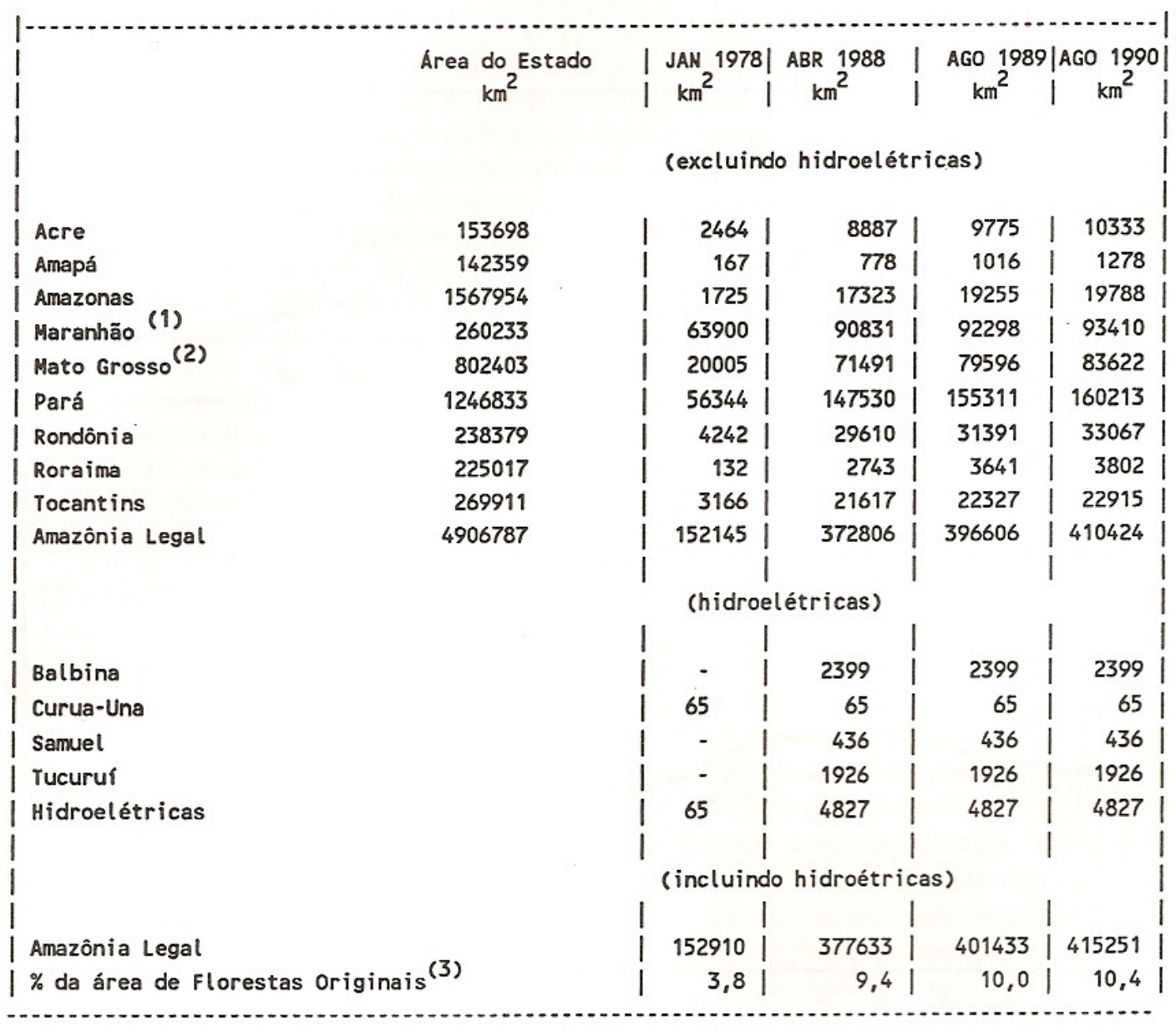

(1) Oeste de 44H

(2) Norte de $16 \mathrm{~s}$

(3) Tomando un valor de aproximadamente $4.000 .000 \mathrm{Km}^{2}$ de superfície coberta originalmente por vegetação florsetal na Amazônia Legal, segundo avaliação Landsat (Meira Filho,1991: Comunicação pessoal).

Fonte: NOBRE,C.A. (1991) Alterações Climáticas Globais e suas implicações para o Brasil. (Contribuição ao Relatório Nacional para a Eco-92. Maio de 1991, CPTEC/INPE, São José dos Campos/SP. 
- na maior parte destas áreas de "queimadas", em solos pobres (arenosos) existe um intenso avanço do babaçu $^{2}$. No trecho de Altamira à Tucuruí (em torno de $400 \mathrm{Km}$ ), e na maior parte do Iriri, constata-se o domínio deste "ecótono", invadindo pastos e lavouras sendo considerado pelos agricultores como uma "praga" de difícil erradicação.

O babaçu representa um "ecótono" que convive naturalmente com a Floresta Equatorial. A retirada dessa Floresta implica num aumento da luminosidade, que, por sua vez, acarreta um ótimo de condiçōes ambientais para a proliferação do babaçu, principalmente nos solos pobres. Não significa este fato um indício de processo de desertificação em curso? Provavelmente sim; principalmente se se considerar que estes fatos vem de há muito extrapolando os limites das ocorrências locais, já abrangendo unidades climáticas intrarregionais dentro da Amazônia, tais como o mádio e o baixo vale do Tocantins, do Araguaia, do Xingu e do Rio Madeira.

Observações de campo realizadas em 1987 em Rondônia, na Bacia do rio Ji-Paraná evidencia que essa área também apresenta uma elevada susceptibilidade à alteração climática, em decorrência da extensa e generalizada retirada da cobertura florestal. Extensas áreas na região de Porto Velho, Ouro Preto D'Oeste, Ji-Paraná e Núcleo Machadinho, estão sendo invadidas pelo babaçu, após a retirada da Floresta Equatorial.

Outro fato a ser considerado é o das relações entre a floresta e o solo, já que a maior parte dos solos florestados da Amazônia são, de modo geral, pobres e arenosos e a ciclagem de nutrientes é basicamente exercida pela própria floresta. Neste caso advém dois novos problemas com a retirada da Floresta: o primeiro, é a decorrencia da diminuição do tempo de permanência da água no solo, devido ao aumento da velocidade de escoamento e consequente diminuição da disponibilidade da umidade para a atmosfera, para as plantas e em cultivos; o segundo problema está ligado às mudanças no albedo da superfície do solo. resultados obtidos por CHARNEY, J. G. (1974) para áreas limítrofes ao Sahel, na África e confirmados por NOBRE (1991) para a Amazônia, demonstram que a diminuição da cobertura vegetal do solo, com o consequente aumento do albedo de $14 \%$ para $35 \%$ pode induzir à diminuição dos totais pluviométricos. No caso desta região da África, esta diminuição das chuvas chegou a aproximadamente $43 \%$, enquanto para a Amazônia a redução pluviométrica foi de $35 \%$.

\section{OS CERRADOS}

Os cerrados ocupam (ou ocupavam) cerca de 1,7 milhão de $\mathrm{Km} 2$ ou cerca de $20 \%$ do território brasilei$\mathrm{ro}^{3}$. De acordo com o Documento preliminar do governo brasileiro para a ECO 92, deste total considera-se que $46 \%$ são aptos à produção agrícola, com base em lavouras de ciclo curto ou pecuária moderna, $34 \%$ à exploração limitada com base em pecuária extensiva e $20 \%$ devem ser preservados. No entanto, este mesmo Documento demonstrou que $37 \%$ da área original do bioma de Cerrado já perdeu sua cobertura primitiva, sendo ocupado atualmente por pastagens e extensas áreas com culturas temporárias, principalmente, soja, milho e arroz.

Do ponto de vista climático, a principal característica é a existência de seis meses de seca, que se extende pelo outono-inverno, ou seja, aproximadamente de abril a setembro. Tratando-se de uma área continental com grande variação latitudinal (aproximadamente entre 12 a $20^{\circ} \mathrm{LS}$ ), a gênese das chuvas depende das interações entre os sistemas extratropicais (escoamento de sul associado à frente polar) e àqueles equatoriais continentais oriundos da Amazônia Centro-Ocidental. Considerando-se pois, que o movimento destes sistemas dependem da circulação geral da atmosfera podemos concluir, que a contribuição do processo de ocupação agro-pecuária na região dos Cerrados, para provocar uma alteração climática à nível regional é praticamente inexistente. Uma das maiores preocupações dos climatólogos, é de que a área do Brasil Central possa sofrer uma diminuição das chuvas (à longo prazo) em função das mudanças climáticas que venham ocorrer na Ama-

(2) Trabalhos de campo executados pelo autor (J.R.Tarifa) desde 1973 na Amazônia Oriental (Marabá-Carajás), com retornos em 1979, 1981 e em Rondonia em 1987/1988, permitiram registrar a progressiva substituição da Floresta Equatorial pelo babaçu, em quase toda a periferia Amazônica (Amazônia Oriental, Meridional no extremo Sudoeste/Rondonia e Acre).

(3) A área core dos Cerrados se estende principalmente pelos estados de Mato Grosso, Mato Grosso do Sul, Goiás, Minas Gerais e Bahia. 
zônia. A análise de imagens de satélites meteorológicos, bem como o estudo do escoamento troposférico em baixos níveis (850 mbs demonstram haver um deslocamento constante (de noroeste para sudeste) de nuvens e vapor d'água da Amazônia Ocidental para o CentroOeste. Este tipo de movimento pode ser observado na figura 2, onde os ventos foram estimados (por satélites geoestacionários) através do movimento das nuvens na estação das chuvas. Assim sendo, apesar de não existirem ainda, simulaçōes capazes de relacionar o desflorestamento da floresta equatorial com a diminuição das chuvas no Cerrado, as evidências observacionais demonstram que uma parte considerável da umidade atmosférica do Brasil Central, é geneticamente formada na Amazônia Centro-Ocidental.

No Cerrado, a utilização em larga escala (vide figura 3) do fogo para a limpeza anual de pastos induz o aparecimento de milhares de focos de fontes de emissão de $\mathrm{CO} 2$ e fumaça no Centro-Oeste. Conforme pode ser observado na foto do satélite NOAA-11 do dia 6 de setembro de 1990, grande parte das queimadas que se imagina serem em áreas de florestas ocorrem na realidade no domínio dos Cerrados. Pelo fato destas queimadas ocorrerem do final do inverno e início da primavera (agosto a outubro) elas provocam alterações substanciais na qualidade do ar.

\section{O NORDESTE SEMI-ÁRIDO}

Caracterizado por clima seco, drenagens intermitentes e depressões interplanáliticas vegetadas com caatingas (AB'SABER, 1977), esse bioma distribui-se pelos estados do Piauí, Ceará, Rio Grande do Norte, Paraíba, Pernambuco, Sergipe, Alagoas, Bahia, Oeste do Maranhão e parte do norte de Minas Gerais, abrangendo uma superfície aproximada de $850 \mathrm{mil} \mathrm{Km2}$. A explicação para a existência deste enorme enclave semi-árido sub-equatorial, no Trópico úmido brasileiro, está exatamente associado à um dos ramos descendentes da circulação de Hadley. As chuvas ficam portanto limitados à atuação irregular da convergência dos Alíseos, ou dependem em nível de mesoescala das interações entre os mecanismos de brisa oceânicas com as serras e escarpas de planalto.

Este quadro de relativa tendência à maior estabilidade atmosférica à nível zonal, evidencia claramente que os processos de alteração climática ligados à exploração agropecuária estarão restritos às mudanças no balanço hídrico e no balanço de radiação solar à nível topo e microclimáticos.

Portanto, a vocação para a intensificação local de "núcleos de desertificação" decorre principalmente das seguintes razões: "regime pluviométrico de baixo índice de precipitaçōes; limitada amplitude e extrema irregularidade (vide figuras 4 e 5); solos rasos com limitada capacidade de retenção de água; elevado número de horas do brilho solar (mais de 3 mil horas de insolação anualmente); ventos secos e quentes com elevada capacidade evaporativa". Este tipo de condições geo-ecológicas, aliada à ocupação através da agricultura convencional e pastagens tem produzido localmente um constante decréscimo da capacidade vegetativa deste bioma. Segundo o Relatório Oficial do Governo brasileiro à Conferencia das Naçōes Unidas (RIO 92), já existem na Bahia $52,5 \mathrm{mil} \mathrm{Km} 2$, onde a vegetação está se tornando esacassa e o solo apresenta-se desprotegido e com índices de erosão acelerada. Em Pernambuco, a área já identificada corresponde à 25 mil Km2. No Rio Grande do Norte as condiçōes climáticas desfavoráveis de baixa pluviosidade $(400 \mathrm{~mm} / \mathrm{ano})$ aliam-se à açăo da prospecção, fazendo da regiāo um dos exemplos mais graves do processo de desertificação. O Piauí em função da retirada da cobertura vegetal para a implantação de projetos agro-pecuários, a partir da década de 1970, apresenta-se com intensos processos erosivos que, por sua vez, provocaram uma drástica redução na produtividade dos solos, bem como o escoamento dos principais corpos d'água.

\section{A FACHADA TROPICAL ATLÂNTICA}

Considera-se aqui como Fachada Tropical Atlântica, todo o domínio dos "mares de morros originalmente revestidos pela Mata Atlântica. O principal controle climático é aquele exercido pela influência oceânica do Atlântico Sul. A presença de um conjunto de terras altas e escarpas litorâneas do Planalto Atlântico, concentra nesta fachada elevados totais anuais pluviométricos (entre 1500 a $4000 \mathrm{~mm}$ anuais). A circulação atmosférica, é marcada pela atuação constante da alta sub-tropical (Sistema Tropical Atlântico) e pelas frequentes 


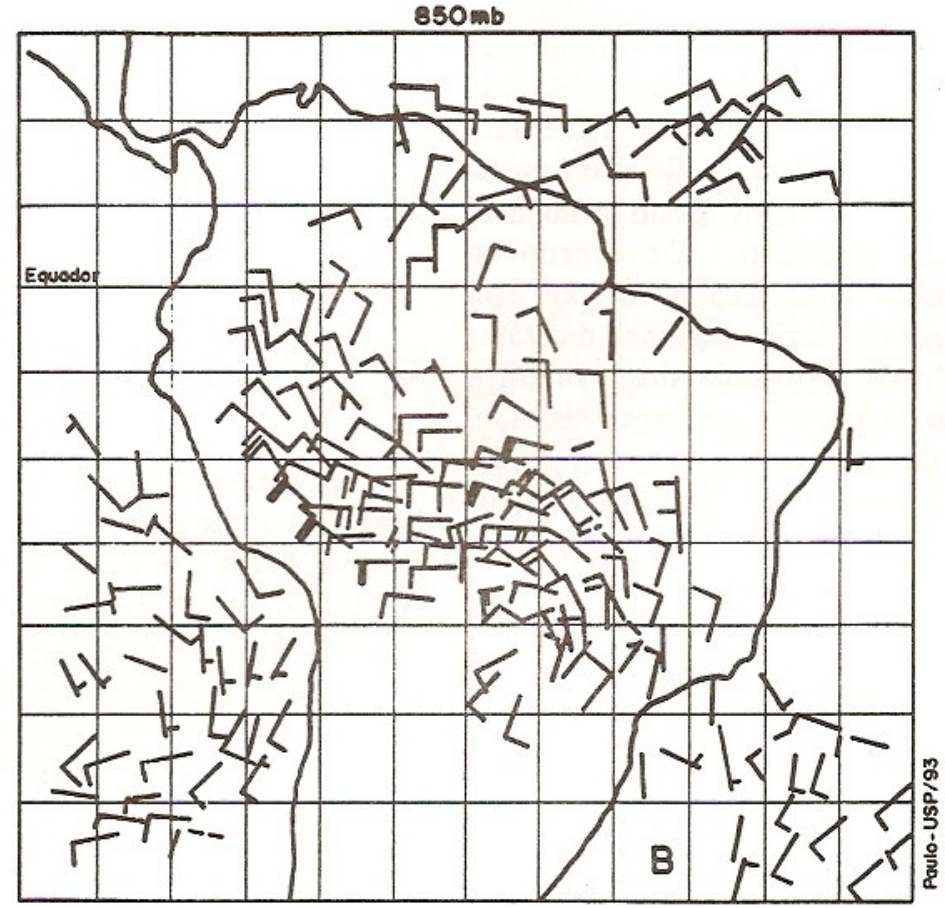

FIGURA 2 DIREÇÃO E VELOCIDADE DOS VENTOS NO NIVELL DE $850 \mathrm{mb}, \mathrm{CF}$.

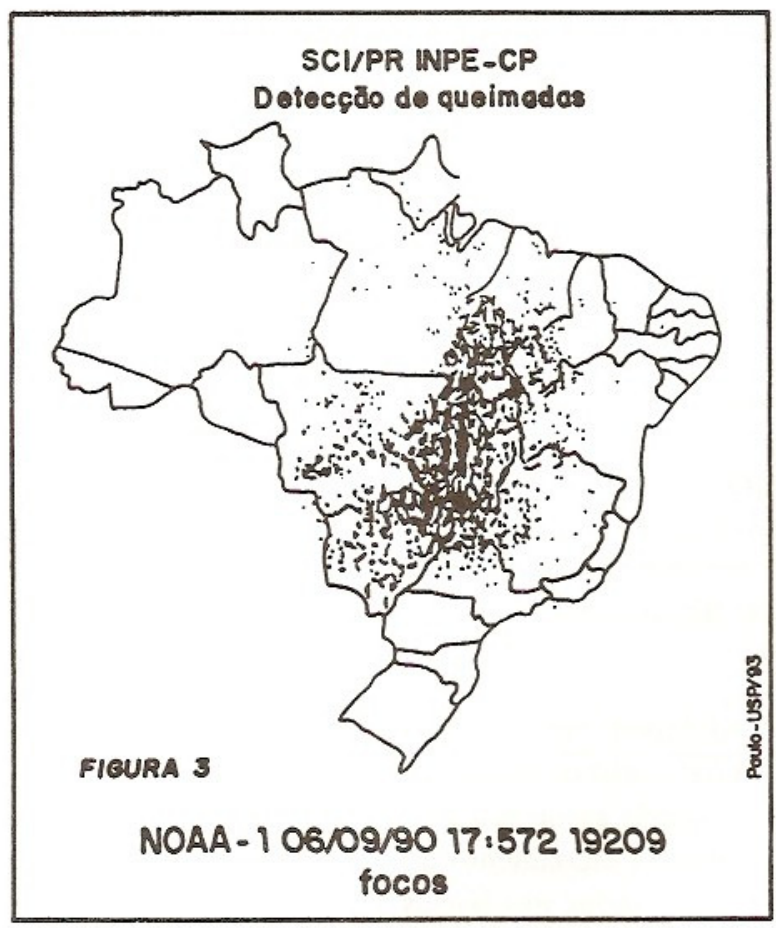


passagens das descontinuidades polares associadas à penetração dos ciclones extratropicais. Portanto, as possibilidades de alteração climática em decorrência do processo de ocupação agrícola é inexistente. No entanto, os lesionamentos na estrutura superficial da paisagem e nos processos hídricos e erosivos, são os maiores registrados no território brasileiro. De acordo co AB'SABER (1977) muitos fatos respondem por esta fragilidade do suporte geo-ecológico regional: o caráter rugoso e mamelonizado da topografia dos morros, a profunda decomposição de granitos, gnaisses e xistos, e, sobretudo, a existência de uma cobertura vegetal primária, num clima tropical úmido com elevados impactos pluviais concentrados.

Removida a cobertura vegetal de grandes setores de morros, inicialmente para a ocupação agricola e posteriormente para a pecuária deixaram sistemas de ravinamentos e boçorocas com vários episódios de deslizamentos e desmoronamentos.

Encontra-se pois nesta Fachada Oriental Atlântica todo um conjunto de processos históricos de apropriação rural-urbana e industrial da paisagem; tendo resultado (principalmente nas áreas metropolitanas) nas situações mais extremas e críticas de espaços poluídos e alterados do território nacional. Portanto, apesar de não se poder afirmar que seja a ocupação agro-pecuária e agro-industrial a responsável por tais fatos. E inquestionável que existem alterações da qualidade do ar na Metrópoles de São Paulo, Rio de Janeiro, Porto Alegre, Salvador e Belo Horizonte, que podem ser parcialmente atribuídos ao estilo de desenvolvimento agrícola (a partir da década de 1970) com um consumo cada vez maior de fertilizantes, agrotóxicos e produtos químicos da indústria, cuja produção encontra-se concentrada nos distritos e áreas industriais. Resta lẹmbrar, que pelo menos para três destas áreas metropolitanas (São Paulo, Rio de Janeiro e Salvador) existem indícios de que esteja ocorrendo a exportação de "chuvas ácidas" para as áreas rurais do entorno metropolitano (pH entre 4,0 e 4,5).

É também nesta Fachada Atlântica que temos assistido os piores casos de eventos extremos de episódios meteorológicos. A elevada pluviosidade associada à situações meteorológicas de bloqueio no escoamento de sul, tem produzido enchentes generalizadas nas bacias do Rio Itajaí-Açú, do Rio Tietê, do Rio Doce entre outros. Uma das causas do aumento da frequência e da magnitude dos danos destes eventos é certamente a mudança areolar na cobertura vegetal destas bacias hidrográficas, onde nem mesmo as cabeceiras e nascentes tem sido mantidas com a vegetação florestal.

\section{OS PLANALTOS E DEPRESSÕES DA BACIA PARANÁ-URUGUAI}

A maior parte dos solos de alta fertilidade do Brasil, estão concentrados nos estados de São Paulo, Paraná, Santa Catarina, Rio Grande do Sul e Mato Grosso do Sul. Antes do surto cafeeiro as florestas cobriam $82 \%$ do território do estado de Săo Paulo, em 1973 essa proporção era de apenas 8,3\%. Da mesma forma, em 1940 quase $90 \%$ do norte do Paraná estava coberto com matas nativas, atualmente estas cobrem menos de $2 \%$ da região. No entanto, parece que esta devastação generalizada das florestas tropicais e de Araucária (no Paraná e em santa Catarina) pela ocupação agro-pecuária não produziu alteraçōes climáticas à nível regional. Não se conhece nenhum tipo de registro comprovado de diminuição do total pluviométrico em função do desmatemento. Provavelmente, isto se deve ao fato, de que as chuvas do Brasil Meridional, tem sua origem associada às oscilações da Frente Polar Atlântica. Assim sendo, as alterações climáticas produzidas dizem respeito à escala topo e microclimática. A única área relatada como tendo agravado o processo de desertificação é aquela dos areais do Sudoeste do Rio Grande do Sul. Segundo dados apresentados por SOUTO, J. (1985) vários municípios, como Alegrete, Santana do Livramento, Cacequi, Santa Maria, São Gabriel e São Francisco de Assis, ocupam áreas com essas características. No município de Alegrete formou-se o denominado deserto de São João, que, segundo os habitantes locais, há cincoenta anos não ultrapassava 12 ha e hoje vai além de 186 ha. Observando-se no mapa de variabilidade temporal da pluviosidade (Figura 5) nota-se que o sudoeste do Rio Grande do Sul, apresentou de 12 a 15 anos com irregularidades significativas (>30\% em relação à normal pluviométrica) no período de 1931 a 1960.

A implantação do PRÓ-ÁLCOOL, (lançado em 1975) a partir de 1986, ampliou-se substancialmente a 


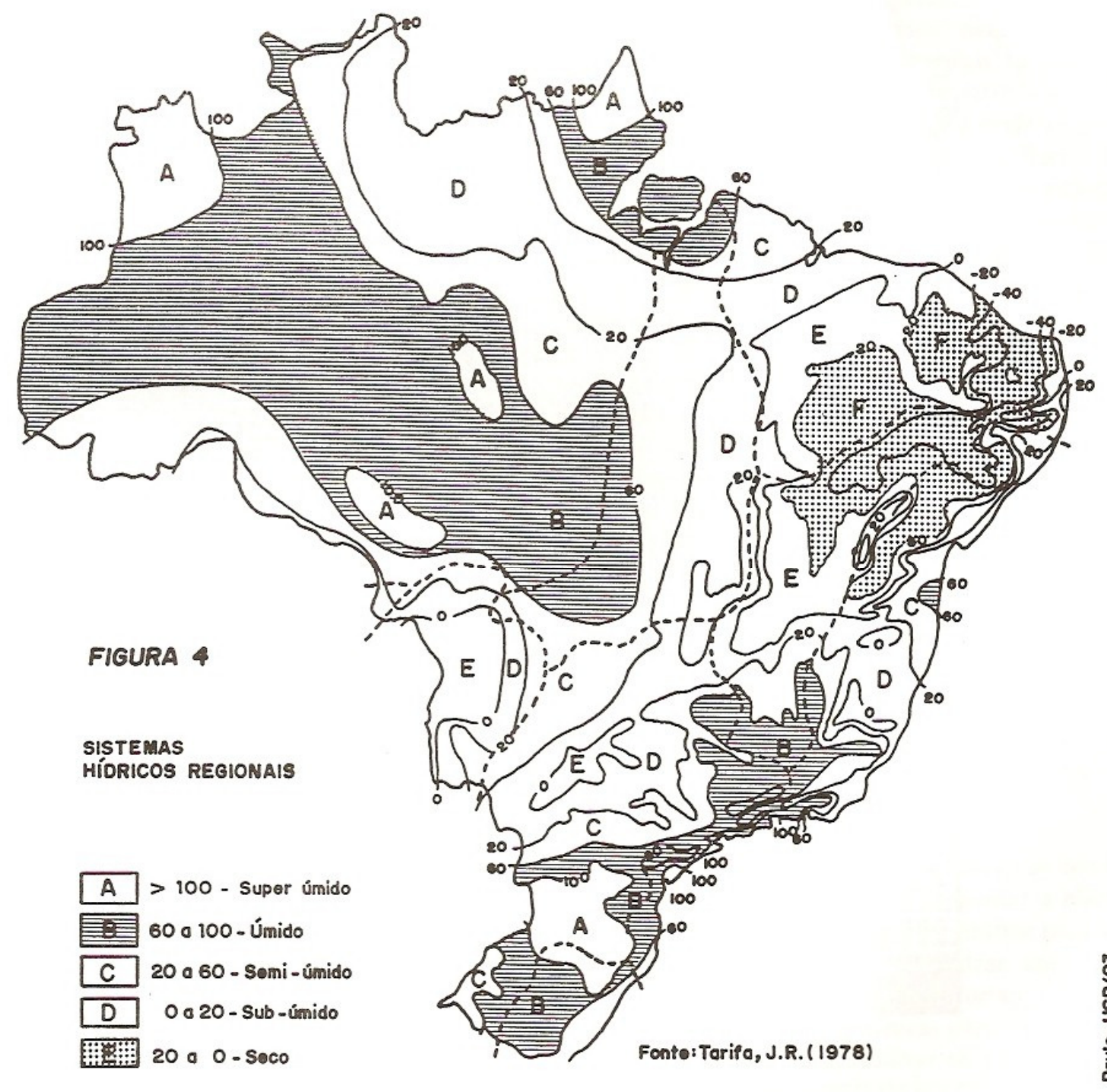




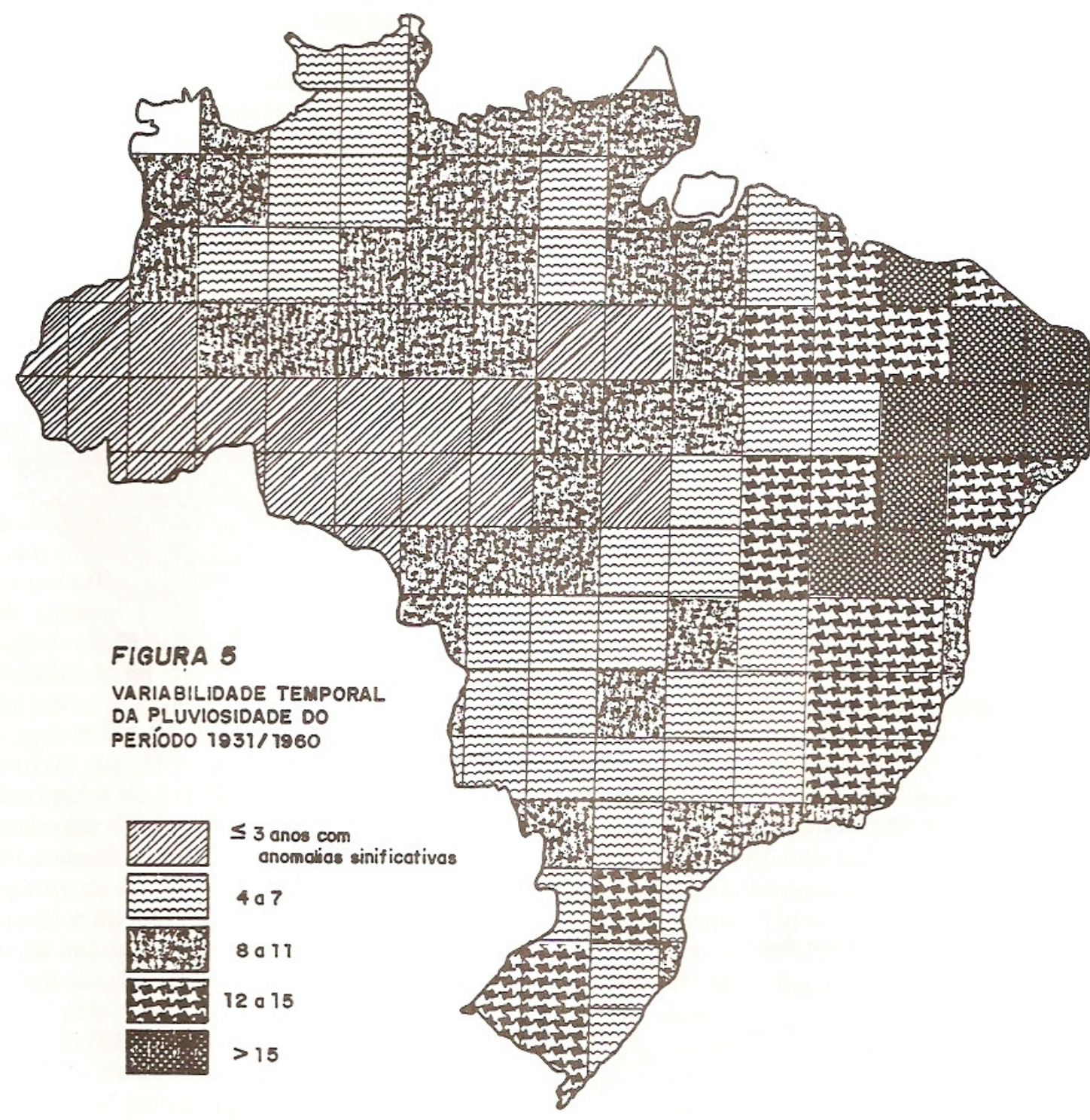

Fonte: Tarifo, J.R. (1978) Recursos Hidricos 
área plantada de cana no estado de Săo Paulo, especialmente no Vale do Rio Paranapanema, e nas regiōes de Ribeirão Preto, Sertãozinho, Piracicaba e Iracemápolis. A produção de cana-de-açúcar e o seu processamento para a obtenção de açúcar e álcool trouxeram como consequência a produção de uma série de resíduos poluidores do meio ambiente. As principais fontes de poluição do ar são a queima da cana e a queima do bagaço.

Além dos efeitos diretos ligados às alterações das escalas inferiores do Clima (Topo e Microclima) o tipo de desenvolvimento agro-industrial (cana e laranja) bem como para a exportação de grãos, de fertilizantes e dos produtos da indústria petroquímica, do qual é extremamente dependente.

\section{CONCLUSÓES}

7.1. O único sistema geo-ecológico do território brasileiro, que apresenta uma interação comprovada entre a floresta e o clima local e regional, é o Continental Amazônico. Com o objetivo de melhor sintetizar e avaliar a magnitude dos impactos foi preparado o Quadro 2. Nele está contida uma listagem classificada dos impactos, e foi possível classificar os impactos quanto ao tipo; possibilidade de ocorrência, grau de impacto, duração e o prazo de tempo (médio ou longo prazo);

7.2. A provável diminuição da pluviosidade (entre 30 a 35\%) em decorrência da substituição regional Floresta Equatorial Continental, por pastagens e cultivos (na Amazônia poderá resultar à longo prazo numa consequênte redução do fluxo de umidade para as áreas agrícolas do Centro-Sul);

7.3. A Fachada Oriental Atlântica, área que concentra a maior parte da população e dos estabelecimentos industriais deve continuar sendo atingido por eventos climáticos extremos, com danos de magnitude crescente;

7.4. A utilização do "fogo" para limpeza anual das pastagens (principalmente no Centro-Oeste), bem como para a queima da cana precisa de maiores investigações para quantificar a influência na piora da quali- dade do ar, e a sua contribuição para as emissões de $\mathrm{CO} 2$

7.5. O Pantanal, representa uma condição climática muito próxima do semi-árido, em função das elevadas temperaturas e da depressão do relevo, que provoca maior estabilidade atmosférica. As alterações produzidas nos altos cursos dos rios formadores do Pantanal, com soja (chapadões revestidos com cerrado), nos processos de sedimentação pode resultar em modificações importantes no escoamento fluvial. Como a maior parte da água no Pantanal, vem do escoamento fluvial e não da pluviosidade local (a evapotranspiração regional é muito elevada) você pode passar de um trecho fértil com umidade do solo, para uma condição hídrica de seca em pequenas distâncias (1 a $2 \mathrm{Km})$;

7.6. A utilização do reflorestamento, como proposta para a recomposição da cobertura do solo e das condiçōes microclimáticas é interessante para áreas degradadas do nordeste semi-árido. No entanto, para áreas do Trópico úmido a sua utilização em larga escala de florestas homogêneas pode resultar em alteraçōes microclimáticas muito pequenas, além do fato do elevado risco de pragas e do próprio fogo serem uma ameaça constante;

7.7. As maiores alterações climáticas resultantes do processo de ocupação agrícola no Brasil, dizem respeito à mudanças no fluxo do escoamento hídrico e são portanto de escala micro e topo climático;

7.8. Qualquer tentativa de melhorar as condições de topo e microclimáticos, para aumentar a eficiência no fornecimento da disponibilidade hídrica para as atividades humanas, passa por encontrar uma soluçấo adequada para a questão agrária. Portanto, não basta apenas encontrar soluçōes técnicas para a questão agrícola, mas principalmente resolver os conflitos fundiários presentes na maior parte do território brasileiro. 


\section{BIBLIOGRAFIA}

AB'SABER, A. N. (1977). Problemática da Desertificação e da Savanização no Brasil Intertropical. Geomorfologia $n^{2} 53$. IGEOG-USP, 19p.

CHARNEY, J. G. (1975). Dynamics of Desert and Drought in the Sahel. Quart Journal Royal Met. Soc., 101(2): 193-202.

NOBRE, C. A. (1991). Alteraçס̃es Climáticas Globais e suas Implicações para o Brasil. Contribuição ao Relatório Nacional para a ECO-92. Maio de 1991. CPTEC-INPE, São José dos Campos.

Relatório Nacional para a ECO-92 (Versåo Preliminar), 1992.

SOUTO, João J.P. (1985). Deserto, uma ameaça? Secr. da Agricultura do Rio Grande do Sul. Estudos dos Núcleos de Desertincação na Fronteira Sudoeste do Rio Grande do Sul Porto Alegre, DRNR, 172 p.

SALATI,E. (1987). The Forest and the Hydrological Cycle in: The Geophysiology of Amazonia. R.E.Dickinson (ed) p.273-287. John Wiley and Sons, 1987.
TARIFA, J. R e ORTOLANI, A. A. (1978). Recursos Hídricos e Agricultura no Brasil. CNPq. Projeto 003 - Recursos Hídricos.

TARIFA, J. R. (1983). O Homem e as Mudanças Climáticas no Brasil. Conferênciaproferida no $3^{\circ}$ Congresso de Agrometeorologia. Campinas, julho de 1983, p. 319 a 338.

TARIFA, J. R. (1983). Climatic Hazards in Southeast Brazil. In IGU - Enviromental Problems (Guide Book), p. 165-185.

VILLA NOVA, N. A. e SALATI, E. Estimativa da Evapotranspiração Potencial na Bacia Amazônica. Climatologia n 6, São Paulo, IGEOG-USP, 43 p. 
Quadro 2

IMPACTOS CLIMÁTICOS DECORRENTES DO USO AGRICOLA MA AMAZÓNIA CONTINENTAL EM AREA DE SOLOS POBRES ARENOSOS

Relação dos Impacros

Aumento local e regional da substituiçăo da floresta equatorial por atividades agrícolas, urbanas.

Razóvel possibilidade de alteração climática à nível local e regional.

Ruptura do equilíbrio dinamico da interação floresta-clima à nível microctimático e local.

mudança no albedo de superficie de $14 \%$ (floresta) para 25 a $30 \%$ (cultivos) e pastagens ou solos arenosos.

Aumento das temperaturas do solo (8 a $10^{\circ} \mathrm{C}$ ) $-0,5 \mathrm{~cm}$.

Aumento das temperatura do ar.

Diminuição do conteúdo de vapor d'água (umidade na camada junto ao solo).

Diminuição do tempo de residencia da água no solo.

Avanço da mata dos cocais (babaçú, ouricuri) sobre as áreas de cultivos e pastagens.

Aumento da velocidade de escoamento superficial.

Legenda

1 - Tipo de Impacto

(B) Benéfico

(P) Prejudicial

2 - Possibilidade de ocorrencia

(C) Certo

(Pr) Provável

(I) Improvável

(D) Desconhecido

3 - Grau de Impacto

(Pe) Pequeno

(Mo) Moderado

(Gr) Grande
Classificação e Magnirude

(P) (C) (Mo) (Pt) (Me)

(P) $(P r)(M 0)$ (T) (LP)

(P) (C) (Mo) (Pt) (Me)

(P) (C) (Mo) (Pt) (Me)

(P) (C) (Mo) (T) (Me)

(P) $(\mathrm{Pr})(\mathrm{Pe})(\mathrm{T})$ (Me)

(P) $(\mathrm{Pr})(\mathrm{Gr})$ (T) (Me)

(P) (C) (Gr) (T) (Me)

(P) (C) (Gr) (T) (Me)

(P) (C) (Gr) (T) (Me) 